\title{
Working memory and phonological processing as predictors of children's mathematical problem solving at different ages
}

\author{
H. LEE SWANSON \\ University of California, Riverside, California
}

\begin{abstract}
The study explored the contribution of working memory (WM) to mathematical problem solving in younger (8-year-old) and older (11-year-old) children. The results showed that (1) significant agerelated differences in WM performance were maintained when measures of phonological processing (i.e., digit naming speed, short-term memory, phonological deletion) were partialed from the analysis; (2) WM predicted solution accuracy of word problems independently of measures of problem representation, knowledge of operations and algorithms, phonological processing, fluid intelligence, reading, and math skill; and (3) a second-order WM factor was correlated with problem solving, suggesting that a general or executive system underlies age-related performance. The results were interpreted as support for the notion that the executive system was an important predictor of age-related changes in problem solving beyond the contribution of math and reading skills, and this system operates independently of the phonological system and domain-specific knowledge in predicting solution accuracy.
\end{abstract}

Working memory (WM) occupies an important niche in recent theories of mathematical story problem processes and is therefore a likely source of age-related differences in children's problem solving (e.g., Hitch, 1978; Kail \& Hall, 1999; LeBlanc \& Weber-Russell, 1996; Swanson \& Sachse-Lee, 2001). WM may be defined as a processing resource of limited capacity, involved in the preservation of information as one simultaneously processes the same or other information (e.g., Baddeley \& Logie, 1999; Engle, Tuholski, Laughlin, \& Conway 1999; Miyake, 2001). It is assumed that because the understanding of mathematical word problems involves a complex interaction of text comprehension and mathematical processes, proficiency of the WM system is related to solution accuracy (e.g., LeBlanc \& Weber-Russell, 1996; Swanson \& Sachse-Lee, 2001). Different theories have been elaborated on how the WM system is used during mathematical as well as reading activities. For example, Just and Carpenter (1992) proposed that many processes operate in parallel, and that WM is used as a common workspace where processes can place partial and final results. In Kintsch's (1998) model of reading comprehension, WM is used to keep a number of text propositions active simultaneously so that they can

This study is part of a longitudinal research program funded by Peloy endowment funds and Institute of Educational Science (USDE R30 $5 \mathrm{H} 020055)$ that assesses the relationship between working memory and mathematics achievement. I am grateful for the comments of two anonymous reviewers and Gerald Tehan on an earlier version of this manuscript. I am also indebted to Carol Sachse-Lee, Fontana School District, for her administrative and technical assistance. Correspondence should be directed to H. L. Swanson, School of Education, Educational Psychology, University of California, Riverside, CA 92028 (e-mail: lee. swanson@ucr.edu). be integrated. This is analogous to comprehending a word problem in which relation, number, and question propositions must be integrated before a solution can be generated (Kintsch \& Greeno, 1985). Thus, WM is used to carry out the integration of propositional units necessary to solve word problems. Accordingly, WM should be an important predictor of age-related changes in solving mathematical word problems.

One model that can be used to capture proficiency in WM as it applies to word problem solving (as well as other domains) and age-related performance is Baddeley's (1986, 1996) multicomponent model. Baddeley $(1986,1996)$ has described WM as a limited-capacity central executive system that interacts with a set of two passive storage systems used for temporary storage of different classes of information: the speech-based phonological loop and the visual sketch pad. The phonological loop is responsible for the temporary storage of verbal information; items are held within a phonological store of limited duration, and the items are maintained within the store via the process of articulation. The visual sketch pad is responsible for the storage of visual-spatial information over brief periods and plays a key role in the generation and manipulation of mental images. Both storage systems are in direct contact with the central executive system. The central executive system is considered to be primarily responsible for the coordinating activity within the cognitive system, but also devotes some of its resources to increasing the amount of information that can be held in the two subsystems (Baddeley \& Logie, 1999).

Because mathematical word problems are a form of text, and the decoding and comprehension of text draws upon the phonological system (see Baddeley, Gathercole, 
\& Papagno, 1998, for a review), age-related differences on problem-solving tasks can be attributed to the phonological loop. ${ }^{1}$ Several studies that have compared older and younger children assume that short-term memory (STM) measures capture a subset of WM performance, the utilization and/or operation of the phonological loop (see Dempster, 1985; Gathercole, 1998; for a comprehensive review). This is because successful performance on STM measures draws upon two major components of the phonological loop: a speech-based phonological input store and a rehearsal process (see Baddeley, 1986, for a review). Regardless of whether or not STM tasks are synonymous with the phonological loop and therefore a subset of WM, research to date indicates that younger children rehearse less and perform more poorly on tasks requiring the short-term retention of order information than older children (e.g., Ornstein, Naus, \& Liberty, 1975), suggesting inefficient utilization of the phonological rehearsal process (see Henry \& Millar, 1993). Because younger children have smaller digit spans than older children, it is possible that they have basic inefficiencies in the storage of phonological input that influence higher level processing, such as comprehending and solving word problems. Developmental differences in the phonological loop, therefore, might be expected to influence some aspects of problem solving, such as computing solutions to problems (e.g., Fürst \& Hitch, 2000). Given that the phonological loop is partly controlled by the central executive system (i.e., the executive system shares some variance with the phonological loop), the development of problem solving may also be directly related to the controlling functions of the central executive system itself (Baddeley, 1996). The present study explores the possibility that executive processing plays a key role in mediating age-related performance in problem solving.

One may consider three competing models as an explanation of the role of WM in age-related problem-solving performance in children: One focuses on processing efficiency at a phonological level, another focuses on the child's knowledge base for arithmetical calculations and components of word problems, and the third focuses on constraints in the storage aspect of WM at a general processing level. One model tested here is that the age-related influence of WM on children's mathematic problem solving is primarily moderated by processing efficiency at the phonological level. Several researchers attribute children's increases in WM span and comprehension to the phonological system (e.g., Perfetti, 1985; Willis \& Gathercole, 2001; see Shankweiler \& Crain, 1986, for a review). One of the possible reasons why WM span increases as a function of age is that older children can name items more rapidly at recall than can younger children. That is, increases in naming up to the late childhood years are assumed to enhance the effectiveness of subvocal rehearsal processes and hence reduce the decay of memory items in the phonological store prior to output (e.g., Henry \& Millar, 1993; Hulme, Thomson, Muir, \& Lawrence, 1984). Furthermore, several studies also suggest that the phonological system, via the phonological loop (phonological store; subvocal rehearsal), influences children's verbatim memory capacity, which in turn supports comprehension (e.g., Perfetti, 1985). These assumptions are consistent with a number of bottom-up models of higher order processing, such as comprehension, which view the primary task of executive processing as one of relaying the results of lower level linguistic analyses upward through the language system (e.g., Shankweiler \& Crain, 1986). Phonologically analyzed information is transferred to WM storage, which in turn is transferred (thus freeing storage for the next chunk of phonological information) upward through the processing system to promote on-line extraction of meaning.

There are clear expectations in the aforementioned model; age-related changes in children's problem solving are related to the phonological system. Mathematical proficiency follows automatically from improvements in phonological processing and, therefore, correlations between WM and problem solving should be significantly weakened if measures reflective of the phonological loop are partialed from the analysis. Thus, if age-related differences in problem-solving performance and WM are moderated by the phonological system, then the relationship between problem solving and WM should be diminished when measures of the phonological system (e.g., articulatory speed, STM) are partialed from the analysis.

A second model concerns whether age-related differences in the child's knowledge base play a major role in mediating the influence of WM on problem solving. Several capacity models suggest that WM is the activated portion of declarative long-term memory (LTM) (e.g., Anderson, Reder, \& Lebiere, 1996; Cantor \& Engle, 1993). That is, WM capacity influences the amount of resources available to activate knowledge (see Conway \& Engle, 1994, for a review of this model). Baddeley and Logie (1999) stated that a major role of WM "is retrieval of stored longterm knowledge relevant to the tasks at hand, the manipulation and recombination of material allowing the interpretation of novel stimuli, and the discovery of novel information or the solution to problems" (p. 31). They further stated that "any increase in total storage capacity beyond that of a given slave system is achieved by accessing either long-term memory (LTM) or other subsystems" (p. 37). Thus, the influence of WM performance on problem solving is related to one's ability to accurately access information (e.g., appropriate algorithm) from LTM to solve the problem. More specifically, a word problem introduces information into WM. The contents of WM are then compared with possible action sequences (e.g., associative links) in LTM (Ericsson \& Kintsch, 1995). When a match is found (recognized), the contents of WM are updated and used to generate a solution. This assumption is consistent with current models of problem solving that are based on "recognize-act" models of a cognitive processor (Anderson et al., 1996; Ericsson \& Kintsch, 1995).

In the present study, I assess whether the retrievability of contents in LTM, specifically the propositions outlined by Mayer and Hegarty (1996), mediates WM and problem 
solving. These LTM propositions are related to accessing numerical, relational, question, and extraneous information, as well as accessing the appropriate operations and algorithms for solution (Hegarty, Mayer, \& Monk, 1995; Mayer \& Hegarty, 1996; Swanson, Cooney, \& Brock, 1993). The present study assumes that one can test contributions of LTM by partialing its influence from the correlations of $\mathrm{WM}$ and problem solving. Thus, the influence of WM on problem solution accuracy should be eliminated when measures related to component knowledge are partialed from the analysis.

Like this model, the third model views executive processes as (1) providing resources to lower order (phonological system) skills and (2) accessing information from LTM. However, the model also views executive processes that are independent of those skills as playing a major role in age-related differences in mathematical problem solving. That is, although individual and age-related differences in problem-solving accuracy are possibly related to the retrievability of contents in LTM (e.g., knowledge of specific mathematical relations, general problem-solving strategies) and the phonological loop, other activities of the executive system may also underlie the influence of WM on solution accuracy (e.g., Swanson \& Sachse-Lee, 2001). For example, several cognitive activities have been assigned to the central executive (e.g., see Miyake, Friedman, Emerson, Witzki, \& Howerter, 2000, for a review), such as control of subsidiary memory systems, control of encoding and retrieval strategies, attention switching during manipulation of material held in the verbal and visualspatial systems, suppression of irrelevant information, and so on, in addition to LTM knowledge retrieval (e.g., Baddeley, 1996; Miyake et al., 2000; Oberauer, Sub, Wilhelm, \& Wittman, 2003). Thus, the third model suggests that a general (executive) system contributes significant variance to age-related differences in problem solving. It is important to note that conflicting findings exist as to whether the influence of WM tasks on higher order tasks (e.g., problem solving, comprehension) is primarily mediated by domain-specific processes or a general system (see Miyake, 2001, for a review). This lack of clarity makes it difficult to determine whether the mechanisms that mediate the link between WM and problem solving in children across age groups reflect the development of independent systems (such as verbal and visual-spatial systems, as reflected in Baddeley's, 1986, model) and/or a common storage system. The present study will explore whether the influence of WM on problem solving reflects a general or domain-specific system by analyzing latent factors related to both systems.

In summary, the purpose of this study was to assess the contribution of WM to age-related performance in children's mathematical problem-solving performance. We considered three possibilities: (1) The relationship between WM and problem solving across age is primarily mediated by a phonological system, (2) the relationship between WM and problem solving is primarily mediated by task-specific knowledge and skills in mathematical calculation, and (3) age-related changes in executive processing can operate independently of the phonological system and resources in LTM and therefore contribute unique variance to problem solving. For this study, performance on measures of naming speed, phonological awareness, and STM was used to assess the phonological system. ${ }^{2}$ Performance on measures of arithmetic calculation and recognition of problem-solving components was used to assess LTM. Performance on verbal and visualspatial WM tasks modeled after the Daneman and Carpenter's (1980) measure format was used to assess executive processing. These tasks are assumed to capture at least two factors of executive processing: susceptibility to interference and manipulation of capacity in the coordination of both processing and storage (e.g., Oberauer, 2002; Whitney, Arnett, Driver, \& Budd, 2001).

The approach used in this study, as in others (e.g., Engle, Cantor, \& Carullo, 1992; Turner \& Engle, 1989), to assess whether a particular system plays the major role in mediating age-related differences in performance was to statistically remove its influence from the analysis. In this study, the influence of the phonological system (e.g., naming speed, STM) or LTM was partialed from the correlation between problem solving and WM. We reasoned that if $\mathrm{WM}$ and problem solving are primarily mediated by a phonological system and/or LTM, then the relationship between WM processing and problem-solving performance should be nonsignificant when measures related to the phonological system and LTM are partialed from the analysis. However, if age-related differences in executive processing also mediate the relationship between WM and problem solving, then the correlations between these two variables will remain significant when measures of phonological processing and LTM are partialed from the analysis.

Two predictions were tested in this study. First, agerelated changes in WM are mediated by an executive system that operates independently of the phonological system and LTM. Thus, age-related changes in WM will be sustained when measures of phonological processing (e.g., naming speed, STM) and LTM are partialed from the analysis. To this end, 8-year-old children's performance was compared with 11-year-old children's performance on measures of WM and phonological processing (e.g., STM, naming speed). This age group was selected to generalize to other studies that have included this broad sample to assess the influence of naming speed on memory span (Cohen $\&$ Heath, 1990). We also selected this age group because we wanted to compare age-related changes in memory in children who vary in math and reading proficiency. Grade 2 is usually considered a beginning point for teaching strategies to solve word problems. In addition, previous studies linking memory span and phonological processing, such as naming speed, have primarily focused on children 7 years of age or younger. These studies show weak to moderate correlations between memory span and naming speed in children 7 years of age and below (see Gathercole, 1998, pp. 6-7 for a review). This occurs because younger children's time-based strategies (i.e., rehearsal) are unstable 
(Gathercole, 1998). Thus, we selected an age level where memory strategies are more stable to better assess the relationship between WM and word problem solving. Elevenyear-olds were compared with 8-year-olds to determine whether the developmental improvement in memory span and problem solving was due to increased executive and phonological processing.

Second, a general WM system accounts for the majority of variance in predicting solution accuracy. We predicted that correlations between WM and problem solving would remain significant after we had statistically removed the influence of phonological processing (naming speed, STM) and measures of LTM (e.g., knowledge of algorithms, arithmetic skills) from the analysis, suggesting that the influence of WM operations on word problem solving is related to a general executive or monitoring system. This contrasting hypothesis assumes that partialing out phonological processing and LTM will not eliminate the role of executive processing on mathematical word problem-solving accuracy. That is, although immaturity in phonological processing in young children may be a major bottleneck in higher order problem solving, executive processing supplements such processing by drawing upon other resources. However, we assumed that the WM tasks involve executive processing and therefore have a domain general function. This is because successful performance on WM tasks also requires the coordination of visual-spatial and/or verbal information that draws from a common system. This assumption is consistent with Baddeley's (1986; Baddeley \& Logie, 1999) model, which views the central executive as coordinating information from the two subsystems (i.e., phonological and visualspatial sketch pad).

\section{METHOD}

\section{Participants}

Sixty-nine children from a southern California public school district participated in this study. From the pool of participants at each participating school, the names of individuals were randomly selected from the district list of potential students. Final selection was related to parent approval for participation and achievement scores. Twenty-five students were drawn from second and third grade and 44 students from fifth and sixth grade. Of the 69 children, 23 were girls and 46 were boys. Gender representation was not significantly different between the two age groups $\left[\chi^{2}(1)=.50, p>.05\right]$. Ethnic representation of the sample was $66 \%$ Anglo, $14 \%$ African American, 16\% Hispanic, and $4 \%$ other (e.g., Chinese, Native American, and Vietnamese).

Means and standard deviations for the selection variables employed in this study are shown in Table 1. All children were administered the Colored Progressive Matrices Test (CPMT; Raven, 1976). Means and standard deviations for raw scores and standard score from the CPMT are displayed in Table 1. An ANOVA of standard scores from the CPMT indicated that the two age groups were comparable $(p>.05)$.

\section{Tasks and Materials}

Mathematical word problem-solving processes. We assumed that a critical component of mathematical problem solving is the

Table 1

Dependent Measures as a Function of Age Group

\begin{tabular}{|c|c|c|c|c|c|c|}
\hline \multirow[b]{2}{*}{ Measures } & \multicolumn{2}{|c|}{$\begin{array}{l}\text { Younger } \\
(n=25)\end{array}$} & \multicolumn{2}{|c|}{$\begin{array}{c}\text { Older } \\
(n=44)\end{array}$} & \multirow[b]{2}{*}{$F$ Ratio } & \multirow[b]{2}{*}{$R^{2}$} \\
\hline & $M$ & $S D$ & $M$ & $S D$ & & \\
\hline Age (months) & 8.46 & .53 & 11.61 & .42 & $722.88 * *$ & .92 \\
\hline \multicolumn{7}{|l|}{ Intelligence/achievement } \\
\hline Calculation & 17.16 & 3.84 & 25.61 & 2.51 & $121.59 * *$ & .64 \\
\hline Standard & 96.10 & 12.76 & 95.39 & 8.18 & .08 & .001 \\
\hline \multicolumn{7}{|l|}{ Raven Progressive } \\
\hline Raw & 27.92 & 3.60 & 31.31 & 2.55 & $20.79 * *$ & .24 \\
\hline Percentile & 63.16 & 22.05 & 62.61 & 20.05 & .01 & .001 \\
\hline \multicolumn{7}{|l|}{ Reading Comprehension } \\
\hline Raw & 8.52 & 3.55 & 16.90 & 4.10 & $75.48 * *$ & .52 \\
\hline Standard & 99.20 & 16.81 & 97.72 & 10.96 & .19 & .001 \\
\hline \multicolumn{7}{|l|}{ Problem Solving } \\
\hline Solution-accuracy & 8.00 & 3.16 & 10.51 & 1.89 & $12.24 * *$ & .16 \\
\hline Question & 5.16 & 1.06 & 5.50 & .73 & 2.45 & .004 \\
\hline Numbers & 5.60 & .64 & 5.45 & .76 & .09 & .001 \\
\hline Goal & 4.52 & 1.04 & 4.79 & 1.09 & 1.05 & .002 \\
\hline Operations & 3.96 & 1.27 & 5.31 & .93 & $25.75 * *$ & .27 \\
\hline Algorithm & 4.16 & 1.49 & 5.27 & 1.01 & $13.48 * *$ & .16 \\
\hline Irrelevant-information & 5.12 & 1.01 & 5.31 & .95 & .65 & .009 \\
\hline \multicolumn{7}{|l|}{ Phonological Processing } \\
\hline Deletion & 16.88 & 2.53 & 18.90 & 1.28 & $19.11 * *$ & .22 \\
\hline Naming rate & 100.48 & 15.59 & 132.48 & 26.15 & $30.93 * *$ & .32 \\
\hline Digit span & 7.80 & 1.69 & 9.90 & 1.63 & $23.78 * *$ & .26 \\
\hline \multicolumn{7}{|l|}{ Verbal Working Memory } \\
\hline Sentence span & 1.44 & .82 & 2.59 & 1.14 & $19.44 * *$ & .22 \\
\hline Digit sentence & 1.56 & 1.22 & 2.43 & .87 & $11.77 * *$ & .15 \\
\hline \multicolumn{7}{|c|}{ Visual-Spatial Working Memory } \\
\hline Visual matrix & 3.76 & 1.71 & 3.95 & 1.07 & .34 & .001 \\
\hline Mapping/dir. & 1.36 & .95 & 2.13 & 1.04 & $9.34 * *$ & .12 \\
\hline
\end{tabular}

$* * p<.001$. 
child's ability to retrieve processing operations that lead to solution. In order to retrieve these operations, a problem solver must have some knowledge of problem-solving heuristics. Two general heuristics were scored in the present study. One reflected the child's ability to understand what the problem was asking and to assign the correct numbers to the representation (referred to as number and question components below) and ignore the irrelevant propositions (referred to as irrelevant information below). Another heuristic reflects the problem solver's attempt to solve and provide an answer to isolated operations and place numbers from the word problem into an equation format (referred to as goal, operations, and algorithm below). To this end, word problems were created that assessed student recall of information. Three booklets were adapted from Swanson et al. (1993) and Swanson and Sachse-Lee (2001). Two booklets contained six problems that included pages that assessed the recall of text from the mathematical word problems. A third booklet contained 12 mathematical word problems to be solved. The categories of mathematical word problems were subtraction, addition, and multiplication. Problems were four sentences in length and contained two-assignment propositions, and one relation, question, and extraneous proposition related to the solution. Readability level for all problems was no greater than 2.0 as verified against graded word lists and the Spache readability formula. Further, the examiner orally read (1) each problem and (2) all multiple-choice response options as the students followed along.

For example, a subtraction problem read as follows: "Darren found 15 pinecones (assignment). He threw 5 pines cones back (assignment). Darren uses pine cones to make ornaments (extraneous). How many pine cones did Darren keep (question)?" (The combination of Sentences 1 and 2 was the relation proposition.) No titles were given to the problems, except the title "Problem 1," "Problem 2," and so on. Depending on the order of presentation, after the problem was presented the students were instructed to turn to the next page, on which the following statement was written: "Without looking back at the problem, circle (from a choice of four options) the question the story problem was asking on the last page." The multiple-choice questions for the sample problem above were as follows: (1) How many pinecones did Darren have in all? (2) How many pinecones did Darren start with? (3) How many pinecones did Darren keep? and (4) How many pinecones did Darren throw back? This page assessed the student's ability to identify correctly the question proposition of each story problem.

On the next page for each problem, the directions asked, "Without looking back at the problem, try to identify the numbers in the problem." The multiple-choice questions for the sample problem above were as follows: (1) 15 and 5, (2) 5 and 10, (3) 15 and 20, and (4) 5 and 20 . This page assessed the student's ability to correctly identify the numbers in the two assignment propositions of each story problem.

Instructions on the next page were as follows: "Without looking back at the problem, identify what the question wants you to find." The multiple-choice questions were as follows: (1) the total number of pinecones Darren found all together, (2) what Darren plans to do with the pinecones, (3) the total number of pinecones Darren had thrown away, and (4) the difference between the pinecones Darren kept and the ones he threw back. This page assessed the student's ability to identify correctly the goals in the two assignment propositions of each story problem.

Instructions for the final page were as follows: "Without looking back at the problem, identify whether addition, subtraction, or multiplication was needed to solve the problem." Students were directed to choose one of the three operations: (1) addition, (2) subtraction, or (3) multiplication. After choosing one of the three operations, children were asked to identify the number sentence they would use to solve the problem: (1) $15 \times 5=$, (2) $15+10=$, (3) $15-5=$, or (4) $15+5=$. This page of the booklet assessed the student's ability to correctly identify the operation and algorithm, respectively.
At the end of each booklet, students were presented a series of true/false questions. All statements were related to the extraneous propositions for each story problem within the booklet. For example, the statement "Darren used pinecones to make ornaments" would be true, whereas the statement "Darren used pinecones to draw pictures" would be false. The total score possible for propositions related to question, number, goal, operations, algorithms, and true/false questions was 12 .

To measure the children's ability to solve mathematical word problems accurately, 12 mathematical word problems, identical in construction to those in the previous booklets, were presented. Children were asked to solve the problem on the next page (story problems were presented on the left-hand side and a blank sheet was on the right-hand side). They were told that they were being timed and that only correct answers would be counted. The examiner read each mathematical word problem aloud and directed the children to follow along in their booklet as the problem was read. Then, children were directed to use the next page to solve the problem, with reminders to "show your work." The total possible correct score was 12.

\section{Phonological Processes and WM}

Several processing measures were administered in this study. As in previous studies, efficient access to resources in the phonological system was measured by performance on the digit span, phonemic deletion, and rapid digit naming tasks (see Gathercole \& Baddeley, 1993, for a review). Previous studies revealed that the digit span and phonological deletion tasks for young children loaded on a single phonological factor (Swanson, Mink, \& Bocian, 1999), whereas the rapid digit naming task loaded on a separate phonological factor (Swanson \& Alexander, 1997, Table 7). Thus, we assume from our studies (Swanson, 1996; Swanson, Ashbaker, \& Lee, 1996), as well as those of others (e.g., Engle et al., 1999) that the digit span STM task is distinct from WM tasks. Three WM subtests selected from the Swanson Cognitive Processing Test (S-CPT; Swanson, 1995) and an adaptation of Daneman and Carpenter's (1980) sentence span task (Swanson, 1992) were administered. These tasks were designed to conform with Baddeley's (1986) definition that they "require simultaneous processing and storage of information" and that they "measure various contents" (pp. 34-35). The processing of information was assessed by asking a comprehension question about material to be remembered, whereas storage was measured by accuracy of item retrieval. The construct validity and reliability of the tasks were established in previous studies (Swanson, 1992, 1996). The reported reliability for all WM tasks ranged from .82 to .94 (Swanson, 1992, 1996). A brief description of each task follows.

\section{Speed and Phonological Processing}

Processing speed. The speed of retrieving phonological representations was assessed using the digit naming speed task of Spring and Capps (1974; also see Swanson \& Alexander, 1997, for a description). This measure involved a continuous list procedure that required children to orally name randomly ordered digits as accurately and quickly as possible. The digits, except the two syllable numerals 7 and 0 , were typewritten on a card in rows in 12-point Courier type. There were 20 groups of digits with 5 digits per group. No spaces were left between digits within groups; consecutive groups were separated by a single space.

Children were instructed to read the digits from left to right as quickly as possible. Two trials were given, separated by a brief rest period. The maximum score possible on each trial was 200; the minimum score was 0 . The dependent measure for this task was performance rate, defined as accuracy/time, with the time score to the nearest second obtained using a stopwatch.

Phonemic deletion. To assess phonetic analysis skills, the phonemic deletion task of Cunningham and Stanovich (1990) was administered. This task required the child to listen as the experimenter presented two sets of words, 10 words each, then remove either the 
initial or final sound of each word and verbalize the remaining word segments. The first set of words (from Cunningham \& Stanovich, 1990) included smart, globe, spark, crib, strip, spot, trick, snipe, smack, and stop. The experimenter instructed the child to "listen carefully to the sound at the beginning of each word. I want you to remove the beginning sound. For example, if I say spark, you would say park." Then, children were given three words for practice (block, grasp, crown).

For the second set of words ( just, craft, lard, drift, cork, tuft, depend, crust, best, and blast), the child verbalized the sound segment that remained after deleting the final phoneme from each word. For instance, the correct response following presentation of the word stimulus blast was blas. The three practice words preceding this set of words included heard, fork, and past. The dependent measure for this task was the total number of word segments accurately produced, with possible scores ranging from 0 to 20 . The split-half reliability reported for this measure was .82 .

Digit span. The span of STM, an index of rote memory, was measured using the Forward Digit Span subtest from the WISC-III (Wechsler, 1991). Stimuli for this task were digit strings of increasing size, which were orally presented by the examiner. Each span level included two trials. The dependent measure was the size of the largest string recalled in exact order for each trial.

\section{Verbal Working Memory}

Sentence span. As a common measure of WM (see Daneman \& Carpenter, 1980; Just \& Carpenter, 1992), this task required the presentation of groups of sentences, read aloud, for which children simultaneously tried to understand the passage and remember the last word of each sentence. The number of sentences in the group gradually increased. After each group, the participant answered a question about a sentence and then recalled the end words. Workingmemory capacity was defined as the largest group of end words recalled. The children's adaptation (Swanson, 1992) of Daneman and Carpenter's (1980) sentence span task was administered. The construction of, and pattern of results associated with, the two measures were comparable. The only difference was that each sentence was read to the child with a 5 -sec pause that indicated the end of a sentence. The original sentence span measure was used with university students, whereas the present measure used a simpler sentence structure and reading vocabulary. The mean sentence reading level was approximately 3.8 . The maximum score possible was 8 and the minimum score was 0 .

Auditory digit sequencing. This task assessed the child's ability to remember numerical information embedded in a short sentence (Swanson, 1992, 1995). Before stimulus presentation, the child was shown a card depicting four strategies for encoding numerical information to be recalled. The pictures portrayed the strategies of rehearsal, chunking, association, and elaboration. The experimenter described each strategy to the child before administration of targeted items. After all strategies had been explained, the child was presented numbers in a sentence context. For example, item 3 stated, "Now suppose somebody wanted to have you take them to the supermarket at $8651 \mathrm{Elm}$ Street?" The numbers were presented at 2sec intervals, followed by a process question ("What was the name of the street?"). Then, the child was asked to select a strategy that represented the best approximation of how he/she planned to practice the information for recall. Finally, the experimenter prompted the child to recall the numbers from the sentence in order. No further information about the strategies was provided. Students were allowed $30 \mathrm{sec}$ to remember the information. Recall difficulty for this task ranged from 3 digits to 14 digits; the dependent measure was the number of sets correctly recalled (range $=0-9$ ).

\section{Visual-Spatial WM}

Visual matrix. This task assessed the child's ability to remember visual sequences within a matrix (Swanson, 1992). The child was presented a series of dots in a matrix; $5 \mathrm{sec}$ were allowed for study.
The matrix was removed, and the child was asked a process question ("Were there any dots in the first column?"). To ensure understanding of "column," the examiner pointed to the first column on a blank matrix (a grid with no dots). After answering the process question, the child was directed to draw dots in the correct boxes on the blank matrix. Difficulty ranged from a matrix of 4 squares and 2 dots to a matrix of 45 squares and 12 dots. The dependent measure was the number of matrices recalled correctly (range $=0-11$ ).

Mapping and directions. This task required the child to remember a sequence of directions on a map (Swanson, 1992). The experimenter presented a street map with dots connected by lines; arrows illustrated the direction a bicycle would go to follow this route through the city. The dots represented stoplights, and lines and arrows mapped the route through the city. The child was allowed $10 \mathrm{sec}$ to study the map.

After the map was removed, the child was asked a process question: "Were there any stoplights on the first street (column)?" The child was then presented a blank matrix on which to draw the street directions (lines and arrows) and stoplights (dots). Difficulty on this subtest ranged from 4 dots to 19 dots. The dependent measure was the number of correctly drawn maps (range $=0-9$ ).

\section{Calculation, Reading Comprehension, and Fluid Intelligence}

The Calculation subtest from the Woodcock-Johnson PsychoEducational Battery (Woodcock \& Johnson, 1989) and the Passage Comprehension subtest from the Test of Reading Comprehension (TORC; Brown, Hammill, \& Wiederholt, 1995) were administered. The test manuals report reliability coefficients for the ages represented in this sample that range from .78 to .96 . As a measure of fluid intelligence, the Colored Progressive Matrices Test (CPMT; Raven, 1976) was administered. The examiner points to a blank square on a page with patterns, indicating that the blank should be filled with the appropriate pattern selection. Respondents are required to figure out the task on their own and to select the appropriate answer by pointing. Patterns become increasingly difficult as the test progresses. The test has an internal consistency reliability ranging from .80 to .90 for ages 7 to 14 . The maximum raw score is 36 and the minimum score is 0 .

\section{Reliability}

Coefficient alphas were computed for each task for the present sample with the influence of age partialed out. Coefficient alphas were $.59, .82$, and .74 for calculation, reading comprehension, and CPMT scores, respectively. Reliability for the word problems solution accuracy was .72. Coefficient alphas for the problem-solving components were $.67, .70, .69, .55, .57$, and .72 for identifying the question, identifying numerical information, identifying the goal of the problem, identifying the correct arithmetical operation, identifying the algorithm, and correctly identifying irrelevant information, respectively. Coefficient alphas were $.62, .52$, and .69 for naming speed, STM, and phonological deletion, respectively. Coefficient alphas were $.70, .64, .64$, and .65 for sentence span, digit/sentence, visual matrix, and mapping/direction, respectively. To enhance reliability, as well as reduce the data, composite scores were the primary measures used in the subsequent analysis.

\section{Procedures}

All participants were tested in their schools by two graduate students. Four sessions of approximately 45 to $60 \mathrm{~min}$ each were required for small-group test administration and one session of 45 to $60 \mathrm{~min}$ for individual administration. During the first session, data were obtained from the TORC and the CPMT. The booklets of problem-solving tasks were administered the next session. Booklets were administered to children in small groups ranging in size from 3 to 5 students. For each problem-solving booklet, the experimenter read the instructions printed on each booklet and administered the 
necessary trials. Children were paced through the booklets by the experimenter, who used a watch to monitor the time. As in Swanson et al. (1993), presentation order of the mathematical word problemsolving booklets was random. There were four presentation orders within booklets, however, related to identifying the question, identifying numerical information, identifying the goal of the problem, identifying the correct arithmetical operation, and identifying the algorithms that were counterbalanced for presentation order. Identifying irrelevant information always occurred last in the booklet. On completion of each task, the booklets were collected. Finally, one 45- to 60-min session was required for individually administered measures. Data collected during this session included the Digit Span subtest of the WISC-III, digit naming speed, phonemic deletion, and the WM tasks.

\section{RESULTS}

The means and standard deviations for problem-solving accuracy, problem-solving components, phonological processing, and WM are shown in Table 1.

\section{Age Comparisons}

Solution accuracy. A significant age effect emerged for solution accuracy $\left[\eta^{2}=.17, F(1,67)=13.32, M S_{\mathrm{e}}=\right.$ $5.58, p<.001]$. The results showed that older children outperformed younger children.

Components of problem solving. A multivariate analysis of variance (MANOVA) of the six problem components (identifying the question, identifying numerical information, identifying the goal of the problem, identifying the correct arithmetical operation, identifying the algorithm, and correctly identifying irrelevant information) as a function of age was significant [Wilks's Lambda $=.66$, $F(7,61)=4.31, p<.0001] . F$ ratios for the univariates are reported in Table 1. We controlled for Type I error using a Bonferroni adjustment (alpha level of .05/6 $=.0083$ ). The univariates showed that significant age effects in favor of older children emerged only for problem components related to correct recognition of operations and algorithms.

To determine whether the six problem-solving components reflected unique constructs, a principal factor analysis was computed. Age was partialed in the analysis. Two criteria were used to determine the number of factors: the Kaiser-Guttman rule of extracting only factors with eigenvalues greater than 1 and Cattell's scree test. According to these two criteria for factor acceptance, both criteria support a three-factor solution, with a final communality estimate of 4.35. Eigenvalues for Factors 1-3 were 1.80, 1.49 , and 1.11 , respectively. The first factor, with a varimax rotation, included components related to goals (.72), operations (.74), and algorithms (.82). The second factor focused on problem-solving components related to question (.83) and number assignment (.52). The final factor loaded meaningfully on the processing of irrelevant information (.86). The first factor we label as knowledge of algorithms/operations and the second as problem representation. The third factor reflected the inhibition of irrelevant propositions. As shown in Table 1, age-related effects in performance were isolated to measures that loaded on Factor 1 (knowledge of algorithms/operations).
Naming speed, STM, and phonological deletion. A MANOVA of phonological deletion, STM, and speed processing scores as a function of age was significant [Wilks's Lambda $=.57, F(3,64)=16.15, p<.0001]$. All univariates were significant (all $p \mathrm{~s}<.001$ ). The older children outperformed younger children (all $p$ s $<.001$ ). To determine whether these measures load on a similar construct, a principal factor analysis, with age partialed, was computed. A single factor emerged (eigenvalue $=1.53$ ), with loadings of .80 on digit naming speed, .74 on phonological deletion, and .58 on digit span. The final communality estimate was 1.53 .

Verbal and visual-spatial working memory. A MANOVA of WM scores yielded significant age group differences [Wilks's Lambda $=.59, F(4,64)=8.72, p<$ $.0001]$. Univariates revealed significant $(p<.001)$ effects for sentence span, auditory digit sequencing, and mapping/ direction tasks. No significant effects emerged for the visual-matrix task.

A further analysis was done to assess whether agerelated differences on the WM tasks were related to a general or specific system. We predicted that if age-related differences in WM performance are related to the executive system, then significant differences between agedifference groups would occur on both verbal and visualspatial WM measures when measures of the phonological system were partialed from the analysis. To investigate these possibilities, a 2 (8-year-old vs. 11-year-old) $\times$ 2 (modality: visual vs. verbal) analysis of covariance (ANCOVA) with repeated measures on the last factor was conducted on composite span scores. Composite scores were created by converting span scores to $z$ scores (based on the total sample) for each verbal and visual-spatial task as a function of the type of memory task. Two composite scores included the mean $z$ scores of tasks related to visual WM (mapping and visual matrix), and verbal WM (sentence span and auditory digit sequencing). Because the literature has discussed the contribution of naming speed and STM separately, we considered each variable as a covariate separately.

The covariate was digit naming speed $[F(1,64)=1.00$, $p>$.05]. No significant two- or three-way interactions with the factor articulation speed reached significance (all $p$ s > .05), satisfying an assumption of ANCOVA (e.g., equivalent slopes between age groups). The ANCOVA indicated that the main effect for age group was significant $\left[F(1,64)=7.31, M S_{\mathrm{e}}=.57, p<.0001\right]$, indicating that 11 -year-old children outperformed 8 -year-old children. The least square mean $z$ scores for 8- and 11-year-old children were -.23 versus .07 for the visual WM composite score, and -.44 versus .30 for the verbal WM composite score, respectively. No other significant effects emerged.

An ANCOVA compared ability groups on WM performance when the influence of STM performance was partialed from the analysis. This was done because of the possibility that the STM composite score may better reflect the phonological system than scores related to digit naming speed. The ANCOVA indicated that the main effect 
for age group was significant $\left[F(1,64)=8.58, M S_{\mathrm{e}}=.53\right.$, $p<.01]$, indicating that 11 -year-old children outperformed 8-year-old children. The covariate, STM, was significant $[F(1,64)=5.49, p<.01]$. The interaction of group $\times \mathrm{STM}$ was not significant $[F(1,64)=.05, p>.05]$. The least square mean $z$ scores for 8- and 11-year-old children were -.08 versus .12 for the visual WM composite score, and -.49 versus .21 for the verbal WM composite score, respectively. No other significant effects emerged.

A similar analysis was computed using performance on the phonological deletion task as a covariate. The ANCOVA indicated that the main effect for age group was significant $\left[F(1,64)=18.84, M S_{\mathrm{e}}=.57, p<.0001\right]$, indicating that 11-year-old children outperformed 8-year-old children. The covariate was not significant $[F(1,64)=.14$, $p>.05]$. The interaction of group $\times$ phonological deletion did not reach significance $[F(1,64)=1.96, p>.05]$. The least square mean $z$ scores for 8 - and 11-year-old children were -.26 versus .03 for the visual WM composite score, and -.68 versus .33 for the verbal WM composite score, respectively. No other significant effects emerged.

Finally, we addressed whether age-related differences in verbal and visual-spatial WM reflect two separate independent systems or two systems that draw on a general system. We assumed the two composite scores (verbal and visual-spatial WM) reflected shared variance (in this case variance related to a domain general system) as well as unique variance (in this case domain-specific variance). To analyze these differences, we had to partition the variance. We used the CALIS (SAS, 1990) program to test whether two first-order factors (the two verbal WM tasks reflected Factor 1 and the two visual-spatial WM tasks reflected Factor 2) captured unique variance and a second higher order factor to reflect shared variance or domaingeneral performance among all the tasks. This forced second-order model was adequate (Bentler's comparative fit index $=.98$, root mean square residual $=.018$ ), and therefore three factor scores were created from this model.

The factor scores of the two age groups were compared. To compute the second-order factor score, we used a Schmid and Leiman (1957) transformation. The procedure removed overlapping variance between the two principal factors (in this case a verbal WM and visual-spatial WM factor) and created a second-order, or g, factor (see Carroll, 1993, for discussion of this procedure). Loadings related to the $\mathrm{g}$ factor and domain-specific verbal and domain-specific visual-spatial factors were used to optimally weight the variables. The two age groups were then compared by partialing out the influence of a phonological composite score (sum of $z$ scores for digit naming speed, STM, and phonological deletion). Performance on the second-order factor was also partialed for the analysis of the two first-order factors to ensure unique and domainspecific variance. An ANCOVA indicated that age-related differences were significant for the domain-general (secondorder) factor $\left[\eta^{2}=.32, F(1,65)=10.70, M S_{\mathrm{e}}=.71, p<\right.$ $.01]$. The first-order visual-spatial factor was also significant $\left[\eta^{2}=.16, F(1,64)=3.93, p<.05\right]$, but not the firstorder verbal domain-specific factor $[F(1,64)=2.44$,
$\left.M S_{\mathrm{e}}=.029, p>.05\right]$. Thus, age-related differences in favor of 11-year-old children emerged for the domaingeneral (least square mean $z$ score $-\mathrm{LSM}=-.71 \mathrm{vs.} \mathrm{.39)}$ and visual-spatial WM (LSM $=-.06$ vs. .07) factors. An ANCOVA was computed on the domain-specific verbal factor, with just the second-factor partialed out. The age effect was significant $\left[\eta^{2}=.17, F(1,65)=8.35, M S_{\mathrm{e}}=\right.$ $.02, p<.001]$. Age-related differences in favor of 11year-old children emerged for the specific verbal WM factor (least square mean $z$ score $-\mathrm{LSM}=-.17$ vs. .11). Compared with the results of the ANCOVA that partialed out phonological processing, the results suggested that first-order verbal WM factor was related to the phonological system.

Taken together, the results support the notion that phonological processes underlie specific variance isolated to the verbal WM measures. The results also showed, however, that age-related differences were pervasive across WM measures. These age-related differences did not vary as a function of naming speed, STM, or phonological processing. More important, age-related differences in WM performance were sustained when the influence of STM and naming speed was partialed from the analysis.

We also determined whether a domain general system was related to problem solving or whether the effects were isolated to the verbal WM or visual-spatial factor scores. To address this issue, the three latent scores related to WM were correlated with problem-solving accuracy. Because these correlations may merely reflect changes in age and phonological processing, we also partialed out the influence of age and the composite score related to phonological processing from the analysis. The partial correlations were significant $(p<.05)$ for the second-order factor $(r=$ .37), but not for the first-order visual-spatial WM factor $(r=.23)$ or first-order factor of verbal WM $(r=.16)$. The results supported the notion that the relationship between problem solving and WM was related to a domain- general system (second-order factor). We also explored whether the second order-factor correlated with measures of fluid intelligence (CPMT) because executive processing has been assumed to mediate this relationship (e.g., Engle et al., 1999). The correlation between second-order factor and fluid intelligence with age partialed from the analysis was significant $[r(66)=.29, p<.01]$. No significant partialed correlation emerged between fluid intelligence and the first-order visual-spatial WM factor $[r(65)=.10, p>.05]$ or between fluid intelligence and the first-order verbal WM factor $[r(66)=-.18, p>.05]$.

\section{Relations Between Problem Solving and Working Memory}

The next analyses examined the relationship between problem solving and WM. We predicted that if executive processing from the WM system plays an important role in accounting for age-related differences in problem solving, independent of the phonological system, then WM measures would predict problem-solving performance after various measures of the phonological system have been partialed from the analysis. We examined this hypoth- 
esis through a series of hierarchical regression analyses in which phonological processes (i.e., STM, naming speed) and WM were the independent variables and problemsolving accuracy was the dependent measure. We also considered whether fluid intelligence, reading comprehension, and calculation mediated performance. In addition, two component measures that correlated highly with solution accuracy, knowledge of operations and knowledge of algorithms, were included in the analysis. Prior to our regression analysis, the intercorrelations between WM and problem-solving measures were examined. To simplify the analysis, composite scores (sum of the $z$ scores for the appropriate tasks) were used for the phonological, WM, and word component measures. ${ }^{3}$

The intercorrelations between phonological processes, $\mathrm{WM}$, word problem processes, and solution accuracy are shown in Table 2 . The age variable was also included in the intercorrelations. Correlations on the left diagonal are zeroorder correlations, and correlations on the right are coefficients with the influence of age partialed out. Because of the number of comparisons, alpha was set to .001. Further, because significant correlations may be merely an artifact of age, chronological age was partialed out in the analysis.

Three important findings are shown in Table 2. First, solution accuracy is significantly related to knowledge of operations and algorithms, phonological processing, WM, calculation, reading comprehension, fluid intelligence, and chronological age. The significant $(p<.001)$ correlations $(d f=66)$ with problem solving, when age was partialed from the analysis, were knowledge of operations (partial $r=.40$ ), knowledge of algorithms (partial $r=$ $.50)$, WM (partial $r=.43$ ), calculation (partial $r=.39$ ), and fluid intelligence (partial $r=.45$ ). Second, phonological processing was significantly related to WM, calculation, reading comprehension, fluid intelligence, and age. However, phonological processing was not significantly related to $\mathrm{WM}$, reading comprehension, and fluid intelligence when age was partialed from the analysis. Finally, WM was significantly correlated with calculation, reading comprehension, fluid intelligence, and age. Significant partial correlations, however, were isolated to reading comprehension $(r=.37)$. The only other significant partial correlation of note was between knowledge of algorithms and fluid intelligence $(r=.40)$.

\section{Predictions of Problem Solving}

Subsequent hierarchical analysis assessed the variables that contributed unique variance to problem-solving performance. We investigated whether the relationship between problem solving and WM was maintained when age, phonological processing, calculation skill, reading comprehension, and fluid intelligence were entered into the analysis. Criterion variables were solution accuracy, knowledge of operations, and knowledge of algorithms. The latter two measures were analyzed because they correlated significantly with solution accuracy. Criterion and predictor measures were $z$ scores converted from raw scores based on the total sample.

For the first set of analyses, we determined the amount of variance in problem solving accounted for by age alone (Model 1). As shown in Table 3, chronological age contributed approximately $19 \%, 26 \%$, and $15 \%$ of the variance to solution accuracy, knowledge of operations, and knowledge of algorithms, respectively. For the second set of analyses (Model 2), we entered phonological processing, WM, and age simultaneously into the regression model. As shown, this model accounted for 35\%, 30\%, and $23 \%$ of the variance in solution accuracy, knowledge of operations, and knowledge of algorithms, respectively. In addition, unique variance was found for WM in predicting solution accuracy, age in predicting knowledge of operations, and phonological processing in predicting knowledge of algorithms.

For the third set of analyses (Model 3), we added fluid intelligence, calculation skill, and reading comprehension to the previous model (Model 2). Model 3 accounted for $49 \%, 40 \%$, and $34 \%$ of the variance in solution accuracy, knowledge of operations, and knowledge of algorithms, respectively. In addition, the results showed that fluid intelligence, calculation skill, and WM contributed unique variance to solution accuracy. Unique variance was found for calculation skill in predicting the problem-solving

Table 2

Intercorrelations Among Problem Solving, Working Memory, and Phonological Processing Composite Scores

\begin{tabular}{|c|c|c|c|c|c|c|c|c|c|c|c|c|}
\hline & 1 & 2 & 3 & 4 & 5 & 6 & 7 & 8 & 9 & 10 & 11 & 12 \\
\hline 1. Solution accuracy & - & .18 & .20 & .22 & $.40 * *$ & $.50^{* * *}$ & .04 & .19 & $.43^{* *}$ & $.39^{* *}$ & .34 & $.45^{* * *}$ \\
\hline 2. Question & .22 & - & .23 & .01 & $.39^{* *}$ & .12 & .09 & .11 & .06 & .15 & .06 & .10 \\
\hline 3. Numbers & .17 & .24 & - & .06 & .22 & .25 & -.12 & .09 & -.06 & .08 & .19 & .01 \\
\hline 4. Goal & .24 & .03 & .07 & - & .20 & .24 & .03 & .08 & .22 & .32 & .23 & .11 \\
\hline 5. Operations & $.53^{* * *}$ & $.39^{* *}$ & .19 & .24 & - & $.75^{* * *}$ & .21 & .22 & -.01 & .32 & .07 & .30 \\
\hline 6. Algorithm & $.58^{* * *}$ & .17 & .24 & .27 & $.80^{* * *}$ & - & .09 & .27 & .17 & .27 & .26 & $.40^{* *}$ \\
\hline 7. Irrel-inf & .09 & .11 & -.11 & .06 & .24 & .14 & - & .17 & -.02 & .18 & -.04 & .01 \\
\hline 8. Phonological & $.41^{* *}$ & .16 & .05 & .13 & $.46^{* * *}$ & $.43^{* *}$ & .19 & - & .20 & .05 & .13 & .34 \\
\hline 9. WM & $.56^{* * *}$ & .12 & -.05 & .26 & .27 & .34 & .03 & $.43^{* * *}$ & - & .21 & $.38^{* *}$ & .31 \\
\hline 10. Calculation & $.55^{* * *}$ & .19 & .04 & .27 & $.58^{* * *}$ & $.47^{* * *}$ & .19 & $.55^{* * *}$ & $.53^{* * *}$ & - & .22 & .25 \\
\hline 11. Reading comp. & $.53^{* * *}$ & .14 & .13 & .25 & $.42^{* *}$ & $.45^{* * *}$ & .05 & $.53^{* * *}$ & $.60^{* * *}$ & $.70^{* * *}$ & - & .35 \\
\hline 12. Fluid intelligence & $.57^{* * *}$ & .15 & .01 & .16 & $.48^{* * *}$ & $.51^{* * *}$ & .06 & $.54^{* * *}$ & $.49^{* * *}$ & $.53^{* * *}$ & $.57^{* * *}$ & - \\
\hline 13. Age & $.44^{* *}$ & .12 & -.01 & .11 & $.51^{* * *}$ & $.39^{* *}$ & .11 & $.63^{* * *}$ & $.51^{* * *}$ & $.84^{* * *}$ & $.74^{* * *}$ & $.49^{* * *}$ \\
\hline
\end{tabular}

Note-Irrel-inf, irrelevant information; phonological, phonological processing. Left of diagonal zero-order correlation, right of diagonal correlations partialed for age. ${ }^{* *} p<.001 .{ }^{* * *} p<.0001$. 
Table 3

Hierarchical Regression Modeling for Criterion Measures of Solution Accuracy, Knowledge of Operations, and Knowledge of Algorithms

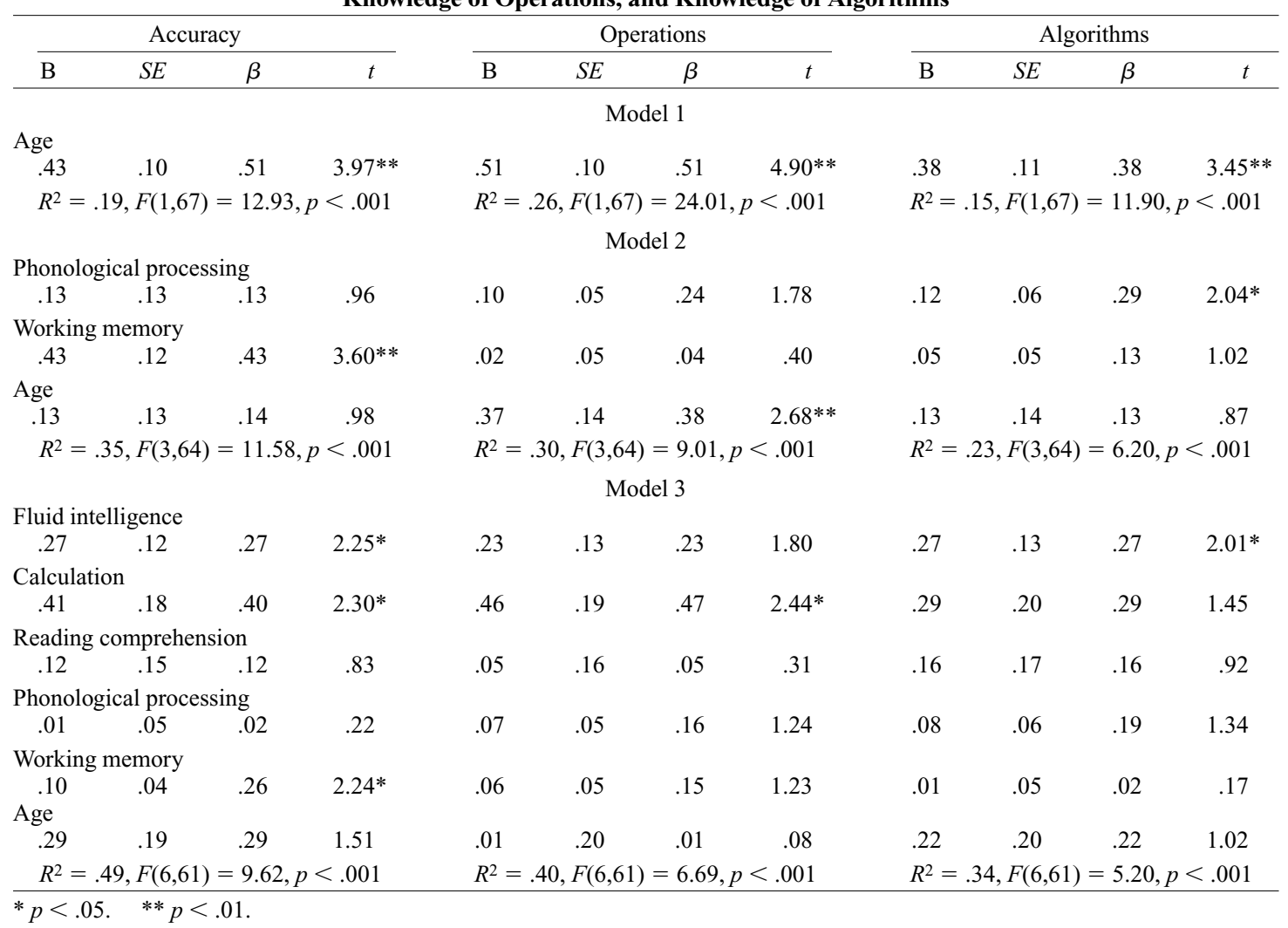

component related to knowledge of operations and fluid intelligence in predicting the component related to knowledge of algorithms.

These three models suggest that WM contributed unique variance in solution accuracy. However, WM was not a significant predictor of performance on the problem-solving component measures. It might be argued that the contribution of WM to solution accuracy would be eliminated once component knowledge was entered into the equation. As shown in Table 4, fluid intelligence, calculation skill, reading comprehension, knowledge of operations/algorithms, phonological processing, WM, and age were entered simultaneously into the regression model. The knowledge of operations/algorithms variables was the sum of the $z$ scores for the knowledge of operations and knowledge of algorithms. This composite score was created because of the high correlation between the two measures. This model (Model 5) accounted for 55\% of the variance in solution accuracy. The important finding was that the significant contribution of fluid intelligence and calculation skill was eliminated in this model. More importantly, composite scores related to WM and knowledge of operation/algorithms were the only variables that contributed significant variance to solution accuracy. Model 6 removed WM from the analysis. This was done to determine the amount of unique variance attributed to $\mathrm{WM}$ in predicting solution accuracy. It was also of interest to determine those variables that contributed unique variance when WM was removed from the analysis. The results showed that Model 6 accounted for $50 \%$ of the variance in predicting solution accuracy. The knowledge of operations/ algorithms was the only variable that contributed unique variance in the prediction

Table 4

Hierarchical Regression Analysis for the Criterion Measure of Solution Accuracy

\begin{tabular}{lcccc}
\hline \multicolumn{1}{c}{} & $\mathrm{B}$ & $S E$ & $\beta$ & $t$ Ratio \\
\hline & Model 5 & & & \\
Fluid intelligence & .18 & .12 & .18 & 1.55 \\
Calculation & .28 & .17 & .28 & 1.59 \\
Reading comprehension & .11 & .15 & .10 & .75 \\
Knowledge of oper./algor. & .17 & .05 & .33 & $3.00^{* *}$ \\
Phonological processing & -.01 & .05 & -.03 & -.29 \\
Working memory & .12 & .05 & .30 & $2.66^{* *}$ \\
Chronological age & .25 & .18 & .25 & 1.40 \\
$R^{2}=.55, F(7,60)=10.61, p<.001$ & & & \\
& Model 6 & & & \\
Fluid intelligence & .23 & .12 & .23 & 1.90 \\
Calculation & .34 & .18 & .33 & 1.87 \\
Reading comprehension & .22 & .14 & .22 & 1.52 \\
Knowledge of oper/algor. & .16 & .06 & .30 & $2.63^{* *}$ \\
Phonological processing & .01 & .05 & .01 & .06 \\
Chronological age & .27 & .19 & .27 & 1.43 \\
$R^{2}=.50, F(6,61)=10.18, p<.001$ & & &
\end{tabular}

$R^{2}=.50, F(6,61)=10.18, p<.001$ 
of solution accuracy. A comparison of Model 6 with Model 5 revealed that WM accounted for approximately $5 \%$ of the unique variance.

A final model partitioned the WM score into a secondorder factor and two first-order factors. The model is shown in Table 5. The second-order factor was calculated as before, using the Schmid-Leiman procedure. The two first-order factors were based on the oblique rotation. Entering the second-order factor into the regression model ensured that the contribution of the two first-order factors reflected variance unique to either the verbal or visualspatial domain. As shown, the final Model 7 accounted for $60 \%$ of the variance. Both the second-order factor and the first-order visual-spatial WM factor contributed unique variance. However, the direction of the beta weights suggests that decreased reliance on the visual-spatial WM factor was related to increased solution accuracy.

In summary, there were three important findings related to the regression analysis. First, a general WM system and component knowledge contributed unique variance to problem-solving accuracy. This variance was significant regardless of whether phonological processing and calculation and reading comprehension were partialed from the analysis. Second, the influence of phonological processing on problem solving was isolated to predicting algorithmic knowledge. However, the unique contribution of phonological processing was eliminated in Models 3 and 4. Finally, removal of WM from the complete model reduced the percentage of variance in the prediction of solution accuracy by $5 \%$.

\section{DISCUSSION}

The purpose of this study was to determine whether a WM system mediated age-related differences in mathematical problem-solving performance, above and beyond age-related changes related to phonological processes, computational knowledge, and domain-specific knowledge related to problem-solving components. We tested three models of WM and its influence on problem solving. One model suggests that lower order processes, such as phonological processing, play a critical role in accounting for age-related changes in problem-solving performance. We tested whether the phonological system moderates the relationship between WM and problem solving. The second model suggests that domain-specific knowledge mediates individual differences in WM and problem solving. The third model suggests that executive processes, which operate independently of the influence of LTM and the phonological system, influence the age-related improvements in problem solving. The results yield three clear findings in support of the third model.

First, the significant variance related to 8-year-old versus 11-year-old children on WM measures was not eliminated by partialing out the influence of phonological processing. Thus, although age increases in WM can co-occur with age increases in phonological processes (STM, naming speed, phonological deletion), the processes appear to
Table 5

Hierarchical Regression Analysis for the Criterion Measure of Solution Accuracy

\begin{tabular}{lrrrc}
\hline & $\mathrm{B}$ & $S E$ & $\beta$ & $t$ Ratio \\
\hline Model 7 & & & & \\
Fluid intelligence & .10 & .12 & .10 & .90 \\
Calculation & .34 & .17 & .34 & $2.00^{*}$ \\
Reading comprehension & .11 & .14 & .11 & .79 \\
Knowledge of oper/algor. & .18 & .10 & .30 & $3.21^{* *}$ \\
Phonological processing & .01 & .15 & .01 & .10 \\
Visual-spatial WM & -1.01 & .49 & -.63 & $-2.06^{*}$ \\
Verbal WM & -.96 & .83 & -.55 & -1.15 \\
Executive (g) WM & .58 & .21 & 1.44 & $2.70^{* *}$ \\
Chronological age & -.27 & .18 & -.27 & -1.44 \\
$R^{2}=.60, F(9,58)=9.53, p<.001$. & & & \\
\hline
\end{tabular}

$* p<.05 . \quad * * p<.01$.

operate independently of one another. That is, age increases in WM were not a direct function of age increases in phonological processes (STM, naming speed). In addition, the hierarchical modeling shows that WM contributes unique variance to problem-solving accuracy beyond the contribution of phonological processes (e.g., STM, naming speed, phonological deletion).

Second, a second-order factor that draws variance from both the verbal and visual-spatial WM tasks correlates significantly with problem-solving performance when the influence of phonological processing is partialed from the analysis. Thus, there is evidence that a domain-general WM system does contribute important variance to agerelated changes in problem solving. The findings support Engle and colleagues' suggestion that the correlation between WM and higher order tasks (e.g., text comprehension) is not a result of skills in the specific component of the WM task, but rather reflects distinct processes that draw upon a common (i.e., modality-free) system (see Engle et al., 1992; Engle et al., 1999; Turner \& Engle, 1989, for a review).

Finally, WM performance predicts solution accuracy when the hierarchical regression analysis includes measures of LTM. Measures of LTM in this study include performance on tasks that relate to calculation, knowledge of algorithms, and knowledge of operations. It has been argued that the executive system functions to access information from LTM (e.g., Baddeley \& Logie, 1999; Conway \& Engle, 1994). Our results suggest, however, that although WM tasks draw information from LTM (e.g., knowledge of components related to problem solving), it may be the monitoring components of WM (manipulation and recombination of material) that play a more important role in age-related changes in mathematical problem solving. However, our results must be clarified because we have merely partialed out the influence of the amount of knowledge available. As indicated by two reviewers of this manuscript, a distinction must be drawn between the amount of WM resources available to produce activation and the amount of knowledge that can be activated. Thus, in our regression analysis we assess the quality of information available, not the capacity to activate LTM knowledge. 
The results merely show that both knowledge of operations/algorithms, an LTM factor, as well as WM predict performance in word mathematical problem solving.

There are three implications of our findings to current literature. First, bottom-up processes (e.g., the phonological system) are not the primary mediators between agerelated increases in WM and problem solving. Of course, these results only apply to the age groups represented in this sample and may not apply to younger children who are learning mathematics and reading skills. The results do coincide, however, with some studies that suggest that phonological skills wane in importance in older children (beyond elementary school years) (e.g., Scarborough, Ehri, Olson, \& Fowler, 1998). Our findings further suggest that although skills associated with phonological processes (i.e., articulation speed and STM) are important to age-related changes in children in calculation and reading comprehension, they are no more important than WM. Such a finding qualifies bottom-up models of problem solving of children by suggesting that if lower order processes related to STM moderate the influence of executive processing (WM) on problem-solving performance, their effects may be indirect or minimal for children who have perhaps met a minimum threshold in mathematics and reading skills.

Second, speed of processing does not appear to moderate age-related WM changes in WM. This finding contrasts with studies in the adult aging literature (Salthouse, 1996). That is, naming speed does not explain all of the variance in age-related WM performance in children in the present study. The results do confirm, however, that robust age-related differences emerge on the naming speed measure. This finding is consistent with the literature suggesting that lower WM and lower STM in 8- than 11-yearold children are a function of lower naming speed rates. However, it appears that these memory processes and naming speed can develop somewhat independently of each other. Additional studies suggest nonredundance between these measures (e.g., Cohen \& Heath, 1990; Johnson \& Anderson, 1998). For example, Cohen and Heath found that memory span naming speed correlated within two different age levels (one age level ranged from 10.2 to 11.7 and the other ranged from 17.3 to 18.9). However, span performance was not weakened between age groups when articulation rate was partialed from the analysis.

Third, our results show that in the context of problem solving, WM and STM operate independently of each other. A common opinion in the literature is that STM tasks are a proper subset of processes of which WM is capable. Further, these studies assume that developmental differences in executive processing are related to efficient lower order processing related to the phonological loop. For example, Crain and Shankweiler (1990) stated, "along with other researchers, we envision the verbal working memory system as having two parts . . . First, there is a storage buffer, where rehearsal of phonetically coded information takes place. This buffer has the properties commonly attributed to STM: It can hold linguistic input briefly ... The second component of working memory is a control mechanism, whose primary task is to relay results of lower-level analysis of linguistic input upward through the system" (p. 542). As a qualification to this view, however, the present analysis suggests that WM can operate independently of STM. This finding is consistent with other experimental work with normally achieving readers (e.g., Engle et al., 1999) and poor readers (Swanson et al., 1996). The implication of this finding is that age-related changes in WM may co-occur with STM, but also maintain some independence from the development of STM.

In summary, we believe our results converge with studies on individual differences suggesting that general resources from a WM system play a critical role in integrating information during problem solving (e.g., Ackerman, Beier, \& Boyle, 2002; Engle et al., 1999; Kyllonen \& Christal, 1990). These models explicitly posit a dual role of WM: (1) It holds recently processed information to make connections to the latest input, and (2) it maintains information for the construction of an overall solution to problems. In terms of individual differences, children who have a large WM capacity for language can carry out the execution of various fundamental problem-solving processes (such as problem representation, problem execution, etc.) with fewer demands on a limited resource pool than children with a smaller WM capacity. As a result, children with a larger WM capacity would have more resources available for storage while representing the problem. On the other hand, children with a smaller WM capacity might have fewer resources available for the maintenance of information during problem solving. This view is supported by our findings showing that the secondorder WM factor correlates significantly with problem solving. Further, this relationship holds (at least for children) even when the influence of phonological loop (articulation speed and STM) is partialed from the analysis.

\section{Alternative Models}

Taken together, the findings in this study indicate that constraints in a domain-general (executive) system contributed significant variance to age-related differences in problem solving beyond the contribution of the phonological system. There are, of course, alternative interpretations to the results that must be considered. One possibility is that 8-year-old children are less resistant to interference (see Harnishfeger \& Bjorklund, 1994, for discussion of this model) than 11-year-olds and that this inference accounts for age-related span differences (e.g., Hasher, Stoltzfus, Zacks, \& Rypma, 1991) and age-related differences in problem solving. For example, the process questions in the current WM tasks constitute a very temporary competing condition with storage. Further, because the WM tasks vary considerably in the types of processing questions the children are exposed to, the pervasiveness of age-related differences across such diverse measures may reflect a general interference condition. As a consequence, 8-year-old children, compared with 11year-old children, have difficulty preventing unnecessary information from entering WM. Therefore, they are more likely to consider alternative interpretations of material 
(such as those asked for in the processing questions) that are not central to the task. This interpretation fits several recent models that explain age-related differences in memory performance as related to inhibitory mechanisms (e.g., Harnishfeger \& Bjorklund, 1994), without positing some form of a capacity limitation within the executive system.

Although we see this model as a viable alternative to the results, we have two reservations. First, only performance by children who answered the process question correctly was analyzed. That is, if a process question was missed, the child's recall of previously stored information was not requested. This procedure is different from those of previous studies (e.g., Daneman \& Carpenter, 1980), which have allowed dissociation between the process question (i.e., it is not necessary for children to answer the process question correctly) and retrieval question in the analyses. Thus, there was an experimenter-imposed association between the process question and the retrieval question. This control also provided feedback to children related to the interpretation and/or relevance of the material to be remembered. Second, it seems to us that the concept of "interference" can be tied to a limited capacity model that allocates resources. Capacity constraints may underlie age-related differences in inhibitory efficiency. This has been suggested in the literature on aging and WM (e.g., Hasher et al., 1991). In short, 8-year-old children may use more capacity related to the executive system than 11-year-old children to inhibit or resist potential interference from irrelevant items.

A second possibility is that this study provides no direct measure of the mental coordination of resources across the verbal and visual-spatial WM task, and therefore the results merely show that verbal and visual-spatial tasks draw finite resources from the same language system. Because this study provides no direct measure of mentally coordinating resources across the verbal and visual-spatial WM tasks, one might argue that the results merely reflect the fact that verbal and visual-spatial tasks draw upon finite resources from a language system. This seems an unlikely interpretation because the significant correlations between $\mathrm{WM}$ as a second-order factor and problem solving were sustained when measures of the phonological loop, as well as domain-specific variance related to verbal WM, were partialed from the results.

In summary, future research should focus on the interaction between executive and lower order processing during the act of problem solving across a broad age span to disentangle the alternative interpretations of the results. It appears, however, that age-related differences that emerge at the central executive level of memory play a major role in predicting solution accuracy. Further research needs to address the variables that circumvent or compensate for age-related differences in WM.

\section{REFERENCES}

Ackerman, P. L., Beier, M. E., \& Boyle, M. O. (2002). Individual differences in WM within a nomological network of cognitive and perceptual speed abilities. Journal of Experimental Psychology: General, 131, 567-589.

ANDERSON, J. R., REDER, L. M., \& Lebiere, C. (1996). Working mem- ory: Activation limitations on retrieval. Cognitive Psychology, $\underline{\mathbf{3 0}} 2$ 221-256.

BADDELEY, A. D. (1986). Working memory. Oxford: Oxford University Press.

BADDELEY, A. D. (1996). Exploring the central executive. Quarterly Journal of Experimental Psychology, 49A, 5-28.

BADDEley, A. D., GATHERCOle, S. E., \& PAPAGNO, C. (1998). The phonological loop as a language learning device. Psychological Review, 105, 158-173.

BADDELEY, A. D., Lewis, V. J., \& VAllar, G. (1984). Exploring the articulatory loop. Quarterly Journal of Experimental Psychology, 36A, 223-252.

Baddeley, A. D., \& Logie, R. H. (1999). The multiple-component model. In A. Miyake \& P. Shah (Eds.), Models of working memory: Mechanisms of active maintenance and executive control (pp. 28-61). Cambridge: Cambridge University Press.

Brown, V. L., Hammill, D. D., \& Wiederholt, J. L. (1995). Test of reading comprehension-Revised. Austin, TX: PRO-ED.

CANTOR, J., \& ENGLE, R. W. (1993). Working-memory capacity is longterm memory activation: An individual differences approach. Journal of Experimental Psychology: Learning, Memory, \& Cognition, 19, 1101-1114.

CARROLL, J. B. (1993). Human cognitive abilities: A survey of factor analytic studies. New York: Cambridge University Press.

Cohen, R. L., \& Heath, M. (1990). The development of serial short-term memory and the articulatory loop hypothesis. Intelligence, 14, 151-171.

Conway, R. A., \& ENGLE, R. W. (1994). Working memory and retrieval: A resource-dependent inhibition model. Journal of Experimental Psychology: General, 123, 354-373.

CRAIN, S., \& SHANKWEILER, D. (1990). Explaining failures in spoken language comprehension by children with reading disabilities. In D. Balota, G. Flores d'Arcais, \& K. Rayner (Eds.), Comprehension processes in reading (pp. 539-555). Hillsdale, NJ: Erlbaum.

Cunningham, A., \& Stanovich, K. (1990). Assessing print exposure and orthographic processing skill in children. Journal of Educational Psychology, 82, 733-740.

DANEMAN, M., \& CARPENTER P. A. (1980). Individual differences in working memory and reading. Journal of Verbal Learning \& Verbal Behavior, 19, 450-466.

DEMPSTER, F. (1985). STM development in childhood and adolescence. In C. Brainerd \& M. Pressley (Eds.), Basic processes in memory (pp. 209-248). New York: Springer-Verlag.

Engle, R. W., Cantor, J., \& Carullo, J. J. (1992). Individual differences in working memory and comprehension: A test of four hypotheses. Journal of Experimental Psychology: Learning, Memory, \& Cognition, 18, 972-992.

Engle, R. W., Tuholski, S. W., Laughlin, J. E., \& Conway, A. R. (1999). Working memory, STM, and general fluid intelligence: A latent variable approach. Journal of Experimental Psychology: General, 128, 309-331.

ERICSSON, K. A., \& KINTSCH, W. (1995). Long-term working memory. Psychological Review, 102, 211-245.

FürST, A. J., \& Hitch, G. J. (2000). Separate roles for executive and phonological components of working memory in mental arithmetic. Memory \& Cognition, 28, 774-782.

GatherCOLE, S. E. (1998). The development of memory. Journal of Child Psychology \& Psychiatry, 39, 3-27.

GATHERCOLE, S. E., \& BADDELEY, A. D. (1993). Working memory and language. Hove, U.K.: Erlbaum.

HARNishFeger, K. K., \& BJorKLUnd, D. F. (1994). A developmental perspective on individual differences in inhibition. Learning \& Individual Differences, 6, 331-355.

Hasher, L., StoltzFus, E. R., Zacks, R. T., \& Rypma, B. (1991). Age and inhibition. Journal of Experimental Psychology: Learning, Memory, \& Cognition, 17, 163-169.

Hegarty, M., MAYER, R., \& MONK, C. (1995). Comprehension of arithmetic word problems: A comparison of successful and unsuccessful problem solvers. Journal of Educational Psychology, 87, 18-32.

Henry, L. A., \& Millar, S. (1993). Why does memory span improve with age? A review of the evidence for two current hypotheses. European Journal of Cognitive Psychology, 5, 241-287. 
Hitch, G. J. (1978). The role of short-term memory in mental arithmetic. Cognitive Psychology, 10, 302-323.

Hulme, C., Thomson, N., Muir, C., \& LaWrence, A. (1984). Speech rate and the development of STM span. Journal of Experimental Child Psychology, 47, 72-87.

JoHNSON, R. S., \& ANDERSON, M. (1998). Memory span, naming speed, and memory strategies in poor and normal readers. Memory, 6, 143-163.

Just, M. A., \& CARPENTER, P. A. (1992). A capacity theory of comprehension: Individual differences in working memory. Psychological Review, 99, 122-149.

KAIL, R., \& HALL, L. K. (1999). Sources of developmental change in children's word-problem performance. Journal of Educational Psychology, 91, 660-668.

KINTSCH, W. (1998). Comprehension: A paradigm for cognition. Cambridge: Cambridge University Press.

KintsCH, W., \& GreENO, J. G. (1985). Understanding and solving arithmetic word problems. Psychological Review, 92, 109-129.

Kyllonen, P. C., \& Christal, R. E. (1990). Reasoning ability is (little more than) working-memory capacity? Intelligence, 14, 389-433.

LeBlanc, M. D., \& Weber-Russell, S. (1996). Text integration and mathematical connections: A computer model of arithmetic word problem solving. Cognitive Science, 20, 357-407.

Mayer, R. E., \& Hegarty, M. (1996). The process of understanding mathematical problem solving. In R. J. Sternberg \& T. Ben-Zeev (Eds.), The nature of mathematical thinking (pp. 29-54). Mahwah, NJ: Erlbaum.

McDougall, S., Hulme, C., Ellis, A., \& Monk, A. (1994). Learning to read: The role of STM and phonological skills. Journal of Experimental Child Psychology, 58, 112-133.

MiYAKE, A. (2001). Individual differences in working memory: Introduction to the special section. Journal of Experimental Psychology: General, 130, 163-168.

MiYAKe, A., Friedman, N. P., Emerson, M. J., Witzki, A. H., \& HowERTER, A. (2000). The unity and diversity of executive functions and their contributions to complex "frontal lobe" tasks: A latent variable analysis. Cognitive Psychology, 41, 49-100.

Oberauer, K. (2002). Access to information in working memory: Exploring the focus of attention. Journal of Experimental Psychology: Learning, Memory, \& Cognition, 29, 411-421.

Oberauer, K., Sub, H., Wilhelm, O., \& Wittman, W. W. (2003). The multiple faces of working memory: Storage, processing, supervision, and coordination. Intelligence, 31, 167-193.

Ornstein, P., NAus, M. J., \& LiBERTY, C. (1975). Rehearsal and organization processes in children's memory. Child Development, 46, 818-830.

Perfetti, C. (1985). Reading ability. New York: Oxford University Press. RAVEN, J. C. (1976). Colored progressive matrices. London: H. K. Lewis.

Riley, M., Greeno, J. G., \& Heller, J. (1983). The development of children's problem solving ability in arithmetic. In H. Ginsburg (Ed.), The development of mathematical thinking (pp. 153-196). New York: Academic Press.

Roodenrys, S., Hulme, C., \& Brown, G. (1993). The development of short-term memory span: Separable effects of speech rate and longterm memory. Journal of Experimental Child Psychology, 56, 431442.

SAlthouse, T. A. (1996). The processing-speed theory of adult age differences in cognition. Psychological Review, 103, 403-428.

SAS Institute (1990). CALIS [Computer software]. Cary, NC: Author.

Scarborough, H., Ehri, L. C., Olson, R. K., \& Fowler, A. E. (1998). The role of phonemic awareness beyond the elementary years. Scientific Studies of Reading, 2, 115-142.

ScHMID, J., \& LEIMAN, J. M. (1957). The development of hierarchical factor solutions. Psychometric, 22, 53-61.

Shankweiler, D., \& Crain, S. (1986). Language mechanisms and reading disorder. Cognition, 24, 139-168.

SPRING, C., \& CAPPS, C. (1974). Encoding speed, rehearsal, and probed recall of dyslexic boys. Journal of Educational Psychology, 66, 780-786.

SwANSON, H. L. (1992). Generality and modifiability of working memory among skilled and less skilled readers. Journal of Educational Psychology, 84, 473-488.
SWAnson, H. L. (1995). S-Cognitive processing test. Austin, TX: PRO-ED.

SWANSON, H. L. (1996). Individual and age-related differences in children's working memory. Memory \& Cognition, 24, 70-82.

Swanson, H. L., \& Alexander, J. (1997). Cognitive processes as predictors of word recognition and reading comprehension in learning disabled and skilled readers: Revisiting the specificity hypothesis. Journal of Educational Psychology, 89,128-158.

SwAnson, H. L., AshbaKer, M., \& LeE, C. (1996). Learning disabled readers' working memory as a function of processing demands. Journal of Experimental Child Psychology, 61, 242-275.

SwANSON, H. L., CoONEY, J. B., \& BROCK, S. (1993). The influence of working memory and classification ability on children's word problem solution. Journal of Experimental Child Psychology, 55, 374-395.

Swanson, H. L., MinK, J., \& Bocian, K. (1999). Cognitive processing deficits in poor readers with symptoms of reading disabilities and ADHD: More alike than different? Journal of Educational Psychology, 91, 321-333.

SwANSON, H. L., \& SACHSE-LEe, C. (2001). Mathematic problem solving and working memory in children with learning disabilities: Both executive and phonological processes are important. Journal of Experimental Child Psychology, 79, 294-321.

TURNER, M. L., \& ENGLE, R. W. (1989). Is working-memory capacity task dependent? Journal of Memory \& Language, 28, 127-154.

WECHSLER, D. (1991). Wechsler intelligence for children-III. San Antonio, TX: Psychological Corp.

Whitney, P., Arnett, P., Driver, A., \& Budd, D. (2001). Measuring central executive functioning: What's in a reading span? Brain \& $\mathrm{Cog}_{-}$ nition, 45, 1-14.

Willis, C. S., \& Gathercole, S. E. (2001). Phonological STM contributions to sentence processing in young children. Memory, 9, 349-363. Woodcock, R. W., \& Johnson, W. B. (1989). Woodcock-Johnson psycho-educational battery. Allen, TX: DLM/Teaching Resources.

\section{NOTES}

1. We focus on the text comprehension aspects of mathematical word problems. Traditionally, individual differences for solving mathematical word problems have been explained in terms of logicomathematical competencies (e.g., deficient numerical structures; Riley, Greeno, \& Heller, 1983). However, a growing body of empirical and theoretical work has shown that children's difficulties in mathematical word problems are strongly related to deficient language and comprehension strategies (e.g., Swanson \& Sachse-Lee, 2001). By focusing on comprehension, we do not diminish the crucial role of computational procedures. Rather, our motivation for studying the comprehension of word problems in children emerges from growing evidence that children have particular difficulty mentally constructing an adequate problem representation (Hegerty, Mayer, \& Monk, 1995).

2. We assumed that age-related differences in STM and naming speed are derivative and/or share a substrate of processes related to the phonological system (Baddeley, Lewis, \& Vallar, 1984). This is because a significant linear relationship between naming speed and STM has been found in many experimental situations (e.g., Roodenrys, Hulme, \& Brown, 1993). Furthermore, naming speed has been interpreted as a measure of how quickly items can be encoded and rehearsed within the phonological loop (McDougall, Hulme, Ellis, \& Monk, 1994). In short, the model assumes that participants who name items quickly can maintain more items than participants who are slow at naming items.

3 . We also computed the regression analysis substituting the composite WM score with the second-order factor score. The patterns in the regression analyses were comparable. This occurred because the composite score and second-order score were highly correlated. The correlation between the WM composite score and the second-order factor score, with age partialed out, was $r(66)=.98$. However, we show the final model that partitioned WM scores as a function of second- and firstorder factors.

(Manuscript received August 7, 2003; revision accepted for publication November 14, 2003.) 